\title{
El gobierno local del agua en las huertas del río Vinalopó durante la época moderna
}

\author{
Tomàs Pérez Medina
}

t.perez@ua.es

\begin{abstract}
Resumen. El régimen valenciano del agua estableció una escala de derechos característica del feudalismo, la división del dominio del agua. Hubo una cesión del uso a los vecinos y de la gestión a los municipios. Así, las huertas son las tierras más valoradas y explotadas. En la cuenca del Vinalopó predominó durante la Edad Moderna el modelo municipal, hay una identificación entre gobierno del agua y administración local. El gobierno del agua dependió de los consejos locales y de sus oficiales y no exclusivamente de los regantes. La gestión y administración del espacio hidráulico es una tarea de la comunidad. Hay que identificar regante con vecino. Los órganos municipales son a la vez instituciones de riego. La participación popular en la gestión de los recursos locales es uno de los objetivos de las comunidades rurales. Igualmente se observa un proceso de diferenciación entre vecino y regante allí donde la desposesión agraria se acelera durante la Edad Moderna. Esta polarización social de la estructura agraria de clases influye en el modelo de gobierno del agua, surgiendo asociaciones de propietarios de agua que controlan las estructuras hidráulicas, los procesos operativos y los órganos de gestión.
\end{abstract}

Palabras clave: Río Vinalopó, regadío, control local, gestión municipal, propiedad.

\begin{abstract}
Local government concerning watering in the Vinalopó river irrigated areas in the Modern Age. The Valencian water regime established a scale of feudal property rights: the division of the water domain. There was a transfer of use to residents and of management to municipalities. Thus, irrigated areas are the most valued and exploited lands. In the Vinalopó valley the municipal model prevailed during the early modern period, there is an identification between water governance and local administration. Water governance depended on local councils and their officers and not just irrigators. The management and administration of the hydraulic space is a task of the community. Irrigators should be identified with neighbors. Town councils are irrigation institutions. Popular participation in the management of local resources is one of the objectives of rural communities. Also a process of differentiation between neighbor and irrigator where land dispossession is accelerated during the early modern period is observed. This social polarization of agrarian class structure influences the pattern of water governance, emerging water homeowners associations that control hydraulic structures, business processes and management councils.
\end{abstract}

Keywords: Vinalopó river, irrigation, local control, town management, property.

$Y$ asi vamos adelante, botes que reman contra la corriente, incesantemente arrastrados hacia el pasado. F. Scott Fitzgerald, El gran Gatsby (1925).

\section{Introducción}

Hace unas décadas los estudios sociales sobre regadíos y estructuras de poder se polarizaron en dos bloques, según se resaltase la autonomía de los espacios irrigados o su vinculación con el poder centralizado. Wittfogel elaboró en 1957 un modelo en el que la agricultura de regadío ostenta un papel crucial: la irrigación a gran escala lleva consigo la centralización burocrática y el despotismo político. Las críticas a la teoría hidráulica de Wittfogel han llevado a elaborar otro modelo analítico: la organización local asociada al regadío, en la que es relevante la autonomía comunitaria para crear sus instituciones, normas de gestión y procedimientos operativos. 
En la presente comunicación estudiamos el gobierno del agua en las huertas históricas del río Vinalopó, al sur del País Valenciano. Los perímetros irrigados se localizan junto a los núcleos de población, aprovechan el débito del río, una rambla, un manantial o un qanat. Toda comunidad rural -populosa como Elx o reducida como Sax- cuenta con un área irrigada, intensamente trabajada, importante para la extracción del excedente agrario. Las huertas son las tierras más valoradas y explotadas.

En la cuenca del Vinalopó predominó durante la Edad Moderna el modelo municipal, hay una identificación plena entre gobierno del agua y administración local. La administración del agua dependió de los concejos locales (Consell General y Consell Particular) y de sus oficiales (justícia, jurats, mostassà, sequier...) y no exclusivamente de los regantes. La gestión y administración del espacio hidráulico es una tarea de la comunidad, identificada con el gobierno local. A principios de la época moderna, en cuanto a herencia medieval, o en las localidades repobladas tras la expulsión morisca de 1609, hay que identificar regante con vecino. Cada una de las nuevas familias cristianas que llegan a inicios del siglo XVII a Monòver, Novelda, Aspe, Elda, Petrer, Crevillent o al arrabal ilicitano de Sant Joan reciben un lote de huerta. Por tanto, los órganos municipales son a la vez instituciones de riego. La participación popular en la gestión de los recursos locales es uno de los objetivos de las comunidades rurales, tanto en los órganos ejecutivos municipales como en los procedimientos operativos de las huertas del río Vinalopó.

Pero igualmente se observa un proceso de diferenciación entre vecino y regante allí donde la desposesión agraria se acelera durante la Edad Moderna. Esta polarización social de la estructura agraria de clases influye en el modelo de gobierno del agua, surgiendo asociaciones de propietarios de agua que controlan las estructuras hidráulicas, los procedimientos operativos y los órganos de gestión. En las últimas décadas de la época moderna observamos en Elx este gobierno oligárquico del agua.

\section{Estatuto jurídico y acceso al agua}

El empleo del agua en cualquier actividad humana está relacionado con el derecho de uso, esto es, con las vías jurídicas de acceso y con el disfrute del elemento (dominio, posesión, propiedad...). El régimen valenciano del agua estaba basado en el dominio del patrimonio real. Según las disposiciones postconquista de los nuevos monarcas del siglo XIII, el agua de las tierras valencianas incorporadas al feudalismo cristiano eran un bien patrimonial de la corona. Con esta aplicación de la norma legal romana que consideraba como un bien público el agua, se frenaba las derivaciones y adquisiciones de agua de ríos y otros cauces mediante presura (Glick, 2007: 164). No obstante, finalizada la conquista militar, el monarca ya había procedido a la redistribución de los medios de producción entre la nobleza participante. Parte del agua y de la tierra, además de molinos y otros equipamientos hidráulicos, pasan en diferentes comarcas a manos señoriales. La corona concede a la nobleza y clero mediante cesión, donación o enajenación el derecho de dominio directo de las aguas. Así, los señores feudales asumen los derechos hereditarios de carácter patrimonial sobre las aguas. Jaime I impuso en los Furs valencianos la concepción de que todo derecho de dominio sobre el agua en el nuevo reino provenía de las transmisiones realizadas por él mismo, por cuanto consideraba todo el reino como conquista propia, adquirido en virtud del ius belli. Todos los bienes adquiridos eran propiedad real y por su voluntad fueron transmitidos a los diferentes poseedores (Febrer Romaguera, 2000: 21-25). El documento 
más conocido sobre la patrimonialización monárquica del agua por Jaume I es el fuero $\mathrm{XXXV}$, rúbrica XVI, que dice así:

Per nos, e per los nostres donam, e atorgam per tostemps a vos tots ensemps, e sengles habitadors, e pobladors de la ciutat, e del regne de V alencia, e de tot lo terme de aquell regne totes, e cascunes cequies franques, e liures majors, e mijanes, e menors ab aygues, a ab manaments, e ab dubiments daygues, e encara aygues de fonts: exceptat la cequia real qui va a Pucol: de les quals cequies, e fonts hajats aygua, e endubiments, e manaments daygues tostemps continuament de dia, e de nuyt. En axi que puscats daquelles regar, e pendre aygues sen alcuna servitud, e servici, e tribut, e que prenats aquelles aygues segons que antiguament es, a fo stablit, e acostumat en temps de sarrabins (García Sanz, 1986: 68).

Los juristas del siglo XVIII recopilan normativas e impulsan instrucciones en pos de un reforzamiento de las posesiones del patrimonio real, cercenando, si es el caso, las normas comunales consuetudinarias de uso y gestión del agua y entrando en conflicto con las jurisdicciones señoriales por el dominio último del agua. Vicente Branchat, desde su cargo de asesor del Real Patrimonio durante el último tercio del siglo XVIII, impulsó el regalismo borbónico en el ámbito hidráulico. Considera Branchat que todas las aguas del antiguo reino valenciano son patrimoniales del rey desde Jaume I. Éste concedió y donó el dominio a nobles y eclesiásticos, poseedores de feudos, pero conservando en la Corona la regalía de los ríos y aguas públicas, y las privadas en los términos realengos (Branchat, 1784: 296). El mismo autor diferencia entre aguas públicas y privadas desde una óptica regalista:

Las aguas se dividen principalmente en públicas y privadas. En la primera clase se comprehenden los rios navegables y no navegables, y todas las que tienen perene y continuo curso, aunque nazcan en terreno de dueño particular. Y las privadas se llaman aquellas, que teniendo origen en territorio de privado dominio, por su corta cantidad, ó por no ser perenes, no pueden emplearse en utilidad pública. Las primeras siempre se han considerado regalía del Principe, que puede disponer de ellas á su arbitrio, y ningún otro sin Real licencia. Pero las segundas son del dueño del campo donde nacen, que puede darles el destino que les sea mas útil (Branchat, 1784: 295).

Además, en las aguas públicas se deben incluir, según el asesor del Real Patrimonio, las corrientes de barrancos y acequias. Jaume I concedió estas aguas a los señores feudales, pero esa donación sólo fue en cuanto a su uso para riego, molienda u otros servicios, disponiendo la corona de la propiedad y dominio de las aguas. Con esta base argumental, el Real Patrimonio podría disponer como públicas de aguas y cauces, para riegos o molinos, sin intermediación de los regantes ni señores. A estas públicas se suman las aguas privadas cuando salen de su término y las privadas sin dueño declarado (Branchat, 1784: 316-319).

De este modo, el régimen valenciano del agua establece una escala de derechos propia del feudalismo: primero la corona que considera las aguas públicas, y ciertas privadas, como una regalía; luego los señores feudales que disponen de ella en sus señoríos y los municipios de realengo en favor de los cuales el monarca ha enajenado el dominio del agua; y, por último, está la tenencia de las comunidades rurales y de sus vecinos a los que se les reconoce el derecho a usar el agua. A partir de esta división del dominio del agua y la importancia del patrimonio real, distinguimos en la cuenca del Vinalopó el régimen jurídico del agua en las tierras de realengo y el régimen del agua en los señoríos baronales.

Durante la época moderna los realengos se concentran en el curso alto de la cuenca del Vinalopó (Bocairent, Banyeres de Mariola, Biar y Beneixama en el reino valenciano y Villena y Sax en la corona castellana). También es de realengo el núcleo meridional de 
Monforte, dependiente de la bailía de Alacant. El sistema de posesión y acceso al agua en el modo de producción feudal, aparte de la patrimonialización monárquica en los realengos, incluye la gestión que realizan los consejos locales y el derecho al uso y usufructo del agua por los vecinos de estas comunidades rurales. La corona se reserva el dominio directo y eminente del agua en sus señoríos y cede a la comunidad el derecho al uso y la administración de ella. Cada vecino accede a una porción de agua como dominador útil, esto es, como usufructuario. La cesión del uso a los vecinos y de la gestión a los consejos municipales mediante esta fórmula jurídica es a cambio del reconocimiento de las comunidades rurales de las prerrogativas y privilegios del rey, señor feudal en los realengos.

La cesión real del agua a las comunidades agrícolas no es a cambio de un canon o censo anual. El cequiaje que abonan los usuarios del agua, recaudado por la comunidad de regantes o la administración municipal, no es un pago de reconocimiento del dominio eminente que tiene el monarca y administra la comunidad, ni una cuota por el consumo, sino para el mantenimiento de la infraestructura hidráulica, la limpieza de las acequias y el abono de retribuciones a los atandadores y acequieros (Glick, 1991: 132. Glick, 2007: 201. Guinot, 2007: 321). En Bocairent aparece este cequiaje: los propietarios de parcelas regadas en la huerta del Collado con aguas del río Vinalopó pagan una contribución que se llama Boalar y sirve para el salario del cequiero, mondar y demás gastos. ${ }^{1}$ Llauradó (1878: 69), al analizar las huertas valencianas, distinguió entre la tacha, que era un canon por los gastos de conservación y administración, y el cequiaje, cantidad destinada a los gastos de limpieza de la red de acequias.

La administración y gestión del agua en los realengos del Vinalopó directamente la realizan los vecinos, regantes y regidores locales. Fijémonos en la cabecera del río Vinalopó. Entre las actuaciones de los oficiales bocairentinos respecto a la administración del agua, que ampliamos en el epígrafe siguiente, está su capacidad para elaborar los libros de riego donde figuran las horas poseídas por cada campesino. En 1598 confeccionaron el llibre capatró e nou cabreu del aigua del riu de Vinalopó fet per ordre dels Jurats i Consell de la present vila de Bocairent en les hereters e regants de l'aigua de dita vila de Bocairent e loch de Banyeres fet per Joseph Ferre, notari escriva de dits Jurats e Consell per ordre d'aquells. En lo any MDLXXXXVIII'.

Según estos registros, documentados entre 1585 y 1780, la distribución y dominio útil del agua de riego del Vinalopó de las villas de Bocairent y de Banyeres de Mariola no está adscrita a la tierra, por lo que puede ser enajenada y regar con su caudal cualquier parcela de los riegos del Collado o del Reg Major. Según Glick (1988: 333, 347), el tipo yemenita también llamado modelo II (Glick, 1989: 58)- se da principalmente en áreas de huertas menores, irrigadas con caudales escasos que convierten el agua en una fuerza productiva muy apreciada. La separación de agua y tierra aparece en los realengos de la cabecera del río Vinalopó y en varios señoríos baronales de los valles y de la desembocadura, como son Novelda y Elx. Entre Bocairent, Novelda y Elx aparecen diferencias climáticas evidentes: $13^{\circ} \mathrm{C}$ de media anual en Bocairent y $18^{\circ} \mathrm{C}$ en la llanura aluvial ilicitana; $655 \mathrm{~mm}$ de precipitación media anual en el nacimiento del Vinalopó y menos de $300 \mathrm{~mm}$ en la desembocadura. Así, pues, la relativa escasez climática de agua no puede ser un condicionante genérico para toda la cuenca del Vinalopó en el momento de explicar la existencia de la separación de tierra y agua o su unión. No es fácil documentar la separación entre la propiedad de la tierra y del agua. Este proceso no se puede atribuir única y exclusivamente a la falta de agua por motivos climáticos, aunque el elemento natural sea, tal

\footnotetext{
${ }^{1}$ Arxiu del Regne de València (ARV): Escribanías de Cámara: Año 1758, exp. 115, fol. 487v.

2 Arxiu Municipal de Bocairent: Caja 37.
} 
como destacó Jean Brunhes (1902), un bien apreciado por su excelencia. La transformación en propiedad autónoma tiene, probablemente, una estrecha vinculación con la expansión medieval y moderna de las huertas. La escasez es, en consecuencia, por la presión social ejercida sobre este recurso natural.

La fragmentación de la propiedad y la división de dominios, propia del feudalismo, también se observa en el agua de los señoríos baronales. El derecho real a disponer de ella hace que mediante cesión, donación o enajenación recaiga, a título de derecho privativo, el poder de disponer del agua en los señores feudales. La nobleza señorial adquiere mediante estas donaciones reales, realizadas tras la ocupación cristiana de las tierras valencianas andalusíes, los derechos dominicales sobre aguas y tierras. Junto a este dominio eminente y directo, convive el dominio útil de los explotadores directos del suelo. La división de dominios característica del feudalismo se plasma en el régimen del agua en los señoríos baronales, pues junto al derecho señorial de disponer del agua existe el derecho campesino de usarla. Esta propiedad compartida típica del feudalismo valenciano es idéntica a la fórmula aplicada a la tierra mediante la enfiteusis (Pérez Medina, e.p.).

Las cartas de población reflejan la propiedad compartida comentada. A través de la nueva carta de población de Elda, publicada el 11 de noviembre de 1611, D. Antonio Coloma Calvillo, conde de Elda, reparte las casas y las haciendas entre los nuevos pobladores. Igualmente distribuye el agua que le corresponde a cada porción de terrazgo. Así, el capítulo XII dice:

Item es estat tractat que les dites hortes y demes terres plantats y terres campes se donen y hajan de donar ab aquella aigua part y portio que fins buy de aygua ban tengut y tenien al temps que les posseien los moriscos segons lo repartiment que Sa Señoria manara fer en la forma desus dita (Sánchez Recio, 2011).

En las localidades del Vinalopó pobladas por emigrantes cristianos tras la expulsión general morisca de 1609, es común el reparto de tierra con su agua, que comporta el pago de un censo enfitéutico anual y perpetuo por cada parcela cultivada. No hay pecho enfitéutico sobre el agua, pero al estar unida a la tierra, los campos irrigados tributan mayor censo que los de secano. Sólo en la villa de Novelda han de pagar 2 dineros por azumbre de agua (Pérez Medina, e.p.) $)^{3}$. Es decir, los derechos de agua son inseparables de la tierra. Reglamentariamente se aplica el principio de inherencia. El capítulo XIII de la carta puebla eldense prohíbe la enajenación del agua separada de la tierra a la cual está adscrita: Item es aixi concertat que los dits nous pobladors y aqui se establiran les dites terres hortes y secans no puixen ahenar ni transportar en manera alguna la terra sens aigua ni l'aigua sens la terra que com es dit desus se repartiran sota pena de perdre la dita terra y aygua. La misma disposión dirige el marqués de Elx a los repobladores de 1611 que ocupan las tierras de los moriscos expulsados en la demarcación de la Séquia de Marxena, imponiéndoles que no se puede vender ni enajenar por ningún caso la heredad sin el agua, ni el agua sin la heredad, sino que lo uno y lo otro ande junto (Gonzálvez Pérez, 1977: 207).

En los Libros de Giradoras de Petrer y en las actas notariales que registran las transmisiones de propiedad durante el último tercio del siglo XVII, no aparece caso alguno

\footnotetext{
${ }^{3}$ Durante el s. XVII aparecen algunas excepciones. En 1614 el conde de Elda y la villa de Elda firman una concordia por asuntos hidrológicos, en la cual los oficiales eldenses aceptan trasladar a Petrer agua del río Vinalopó. Por este concierto del agua de Elda el conde obtiene una renta de 75 libras anuales que paga cada parcela de viña de 4 tahúllas a razón de 15 sueldos por parcela (Pérez Medina, 1995: 90).
} 
en el cual tierra y agua queden separadas. Todas las ventas de parcelas irrigadas de Petrer, notarialmente registradas, especifican que la superficie transmitida cuenta ab son just Pecho y aygua conforme la giradora de la present Vila ${ }^{4}$. Parece, pues, que se sigue en la normativa repobladora postmorisca de Petrer, Elda, Monòver, Novelda, Asp, Elx y Crevillent el modelo sirio (Glick, 1988: 347) o tipo I (Glick, 1989: 58) de distribución de las aguas, en el que agua y tierra son inseparables (principio de inherencia) y donde el método de distribución del agua es proporcional al caudal total existente.

Otra cuestión es la separación de tierra y agua documentada en estas baronías en los siglos XVIII y XIX. La carta puebla de Monòver dispuso la unión de tierras y agua, pero el Padrón de Riqueza de 1818 registra propietarios de agua en cada una de las huertas del término. El agua está distribuida según tiempos fijos, en horas. En las huertas de Monòver, aparecen un total de 81 propietarios de agua, esto es, únicamente el $13 \%$ de los propietarios registrados en el padrón de riqueza territorial de 1818. Menor es aún el porcentaje si tenemos en cuenta que la población de Monòver por estas fechas es de 1.788 casas, por lo que sólo el 5,1 \% poseen agua de riego. El líquido elemento que riega 200 hectáreas, distribuidas en una docena de perímetros por el término monovero, estaba controlado por un reducido número de vecinos propietarios. Los mayores aguatenientes controlan $2 / 3$ del agua acumulada en las balsas ${ }^{5}$.

Las estipulaciones de las cartas de población de 1611 y la identidad entre vecino y regante han cambiado totalmente a finales de la época moderna. Ha habido un proceso de desposesión, a la vez que una concentración de la propiedad del agua en una oligarquía local que controla los medios de producción y el gobierno local. Este proceso desemboca en el cambio del modelo de administración del agua.

\section{Consells, acequieros y campesinos}

A lo largo de las centurias modernas se creó un complejo sistema hidráulico en la cuenca del Vinalopó. 10.000 hectáreas eran regadas y un centenar de molinos hidromecánicos funcionaban a finales del antiguo régimen entre Bocairent y Elx. Son espacios hidráulicos locales que entrado el siglo XIX, tras las expansiones seculares, aún son gestionados como una sola unidad municipal en cada población. Podemos destacar las más de 1.000 hectáreas de las huertas de Elda y Novelda, gestionadas como un apartado más del poder local. Sobresale Elx, con casi 3.000 hectáreas, en una múltiple e histórica red de riego y molienda, con dos unidades de gestión privatizadas por la oligarquía a finales del siglo XVIII. El control local ha sido la característica en estos casos.

Wittfogel (1966) elaboró un modelo en el que la agricultura de regadío tiene un papel crucial en ambientes áridos. Su propuesta de agricultura hidráulica se basaba en el destacado papel del gobierno estatal, en el predominante carácter agroadministrativo y agoburocrático con patrones centralizados y despóticos. El estado crea un orden agrícola, en el que destaca la irrigación, mediante grandes obras hidráulicas, la obligación de prestación de trabajo y una burocracia jerarquizada. Esta secuencia también la aplica a escala aldeana con delegados gubernamentales o vecinos elegidos que gozaron con toda probabilidad de un poder considerable [que], asistido por un escriba y uno o varios policías, puede llegar a ser una especie de déspota local (Wittfogel, 1966: 145).

\footnotetext{
${ }^{4}$ Arxiu de Protocols Notarials de Monòver: notario Josep Gil, 19 de marzo de 1667.

${ }^{5}$ Arxiu Municipal de Monòver: Caja 1690, legajos 1A-1E.
} 
Glick (1988), siguiendo las propuestas metodológicas de Arthur Maass, criticó el despotismo hidráulico de Wittfogel. En su obra sobre el regadío medieval valenciano añade un elemento a la proposición pionera de Jean Brunhes en la que medio físico y organización del regadío se interrelacionan: Glick señala que la organización comunitaria posee un componente cultural plasmado en sus técnicas, estructuras e instituciones hidráulicas. La impronta islámica es una característica destacada por el autor estadounidense, además de la organización comunitaria de los regadíos. La propuesta que defiende es la existencia de un poder local fuerte y cohesionado, como uno de los objetivos de la comunidad de regantes, que se opone a la teoría de Wittfogel sobre la existencia de sistemas políticos centralizados allí donde aparecen redes complejas de regadío que precisan grandes trabajos hidráulicos (Retamero, 2009).

La administración monárquica y los grandes señores feudales fueron, sin duda, activos partícipes en las obras de infraestructuras de riego, pero ello no supuso su participación directa en el gobierno local del agua. En el Vinalopó hubo importantes obras que transformaron los espacios hidráulicos, donde la iniciativa comunitaria es acompañada por los poderes exteriores: la creación en la segunda mitad del siglo XV de la huerta del Collado con aguas del río Vinalopó en Bocairent, la construcción de la Acequia del Conde eldense con el incremento de la superficie irrigada, las destacadas presas de Elx, Petrer y Elda del siglo XVII, o las desecaciones de los almarjales de Elx y de la laguna de Villena a finales del periodo moderno. Pero hubo muchas más actuaciones a pequeña escala protagonizadas exclusivamente por el campesinado. Tal como señala Palerm-Viqueira (2005), cabe diferenciar en nuestro caso un locus de autoridad exterior, la administración burocrática. La Real Audiencia valenciana, los gobernadores de Orihuela y Xàtiva y los delegados reales o señoriales que intervienen en contados casos, como son conflictos y negociaciones intercomunitarios, participación en grandes obras o actuación de peritos especialistas. El otro locus de autoridad es interior, de autogestión y gobierno de los regantes, con capacidades locales y sin personal especializado, ya que son los vecinos regantes quienes actúan de oficiales, realizan los procedimientos operativos de distribución del agua y generan conocimientos y habilidades comunitarias.

Glick (1988: 288-289) distinguió dos modelos simultáneos para la organización cristiana bajomedieval del gobierno de las aguas: uno celular, centrado en las comunidades de regantes que elegían a sus oficiales, y otro municipal, en el que la administración del espacio irrigado formaba parte del gobierno local. En la cuenca del Vinalopó predominó durante la Edad Moderna el modelo municipal. El sistema de riego local forma parte del territorio municipal y hay una identificación plena entre gobierno de las aguas y administración local. Toda comunidad rural cuenta con un área irrigada, intensamente trabajada que, como en el caso de Petrer, es la única tierra registrada en la documentación señorial elaborada para la extracción del excedente agrario. Son, pues, las tierras más valoradas y explotadas. Por tanto, la gestión y administración del espacio hidráulico es una tarea de la comunidad, integrada en alto grado en el gobierno local. La organización comunitaria y los sistemas hidráulicos locales son isomorfos: las normas de riego, reglas y ordenanzas comunitarias; los derechos del agua de riego se relacionan con la pertenencia a la comunidad y con la participación en la vida vecinal; la gestión del agua se hace conjuntamente a la de otros bienes comunes y de otros asuntos sociales...

Guinot (2007a, 2007b) plantea la dualidad de la organización social de los regantes -celular y municipal- en el marco de la colonización feudal del siglo XIII, con el interés centrado en los nuevos colonos cristianos que se apropian y reparten un conjunto de infraestructuras y 
sistemas hidráulicos de tradición andalusí, de huertas organizadas, de usos y costumbres en la gestión del agua. Son cristianos que heredan una diversidad de huertas musulmanas en las cuales la sociedad feudal introdujo modificaciones. Dos ejemplos del Vinalopó aportamos a modo de esbozo para esos años del siglo XIII de herencia islámica de regadío y agua y de instauración feudal.

Mediado el siglo XIII los señoríos manuelinos se extendían por la cuenca del río Vinalopó. La organización de los nuevos dominios la inició el infante don Manuel con la entrega de casas, tierras y aguas a aquellas familias cristianas que poblaron estas tierras. En unos lugares conservaban su cultivo las comunidades mudéjares, pero en otros, como es el caso de Elx, tras la protesta de la población musulmana entre 1261-1266, se produjo un vacío que era preciso cubrir. En Elx el colectivo musulmán fue trasladado extramuros de la Vila, a la margen derecha del río Vinalopó donde se formó el Raval, nuevo núcleo musulmán, quedando reservada la Vila para los pobladores cristianos. El 7 de diciembre de 1267 el infante don Manuel otorga a los nuevos vecinos cristianos de Elx los heredamientos del término y les garantiza su tenencia enfitéutica y hereditaria (Cabanes Catalá, 1995: 103-105). El 5 de abril de 1268 otorga en Burgos otro privilegio en el que, entre otros aspectos, manda que el agua que avedes, quella aya todo el concejo comunalmente, también la de Benicanal commo de los otros logares sata que yo vaya a la terra (Cabanes Catalá, 1995: 106). En la villa de Elx el infante don Manuel dona el 20 de junio de 1269 al consell de Elx et confermoles la partición de las cases, et de los heredamientos et de las ayguas y dona a los pobladores de Elx, presentes y futuros, el agua con que se regavan las acarias, do son d'estas heredidades, que la ayan assí como la solien aver los moros en el so tiempo (Cabanes Catalá, 1995: 106-107).

En estos privilegios citados se señalan las leyes generales referentes a esa administración hidráulica musulmana, pero que desconocemos en detalle. Tras la reorganización del espacio por la nobleza feudal, surge la dualidad administrativa del regadío de Elx que se iba a mantener hasta el siglo XIX: confinamiento musulmán en el Raval, en la margen derecha donde regaba la Séquia de Marxena, con la gestión del riego y el reparto del agua realizado por la aljama y el alamí; y asentamiento de los pobladores cristianos en la Vila, en la margen izquierda del río Vinalopó donde regaba la Séquia Major, gestionada, gobernada y organizada por los jurados del consejo municipal de la Vila (Guinot y Selma, 2003).

Las comunidades islámicas medievales de Petrer y Elda contaban con huertas. Del Llibre dels fets de Jaume I (García Sanz, 1995: 243) deducimos que las aljamas y los vells habían firmado pactos con el rey castellano y sus primeros señores feudales para mantener su autonomía y la gestión de sus huertas. Durante los siglos bajomedievales la aljama eldense está muy activa en la gestión de las aguas de riego que llegan por el río Vinalopó a su huerta (Pérez Medina, 1997: 46-49). Así, pues, podemos inferir a partir de los casos de Elx, Petrer y Elda la cesión del control del sistema de riego y la huerta a los pobladores de las alquerías musulmanas por el mantenimiento de las aljamas (Monjo, 2012) o a los nuevos emigrantes cristianos del siglo XIII.

Para la época moderna contamos con más documentación que nos permite conocer el control local del agua: los libros de consejos, las cuentas de claverías, los expedientes judiciales de las cortes locales, los conflictos sustanciados en la Real Audiencia o en la corte del Gobernador y las nuevas cartas pueblas de 1611. En esta documentación hay un reconocimiento de la comunidad campesina, de su derecho a utilizar los recursos naturales y de la capacidad jurídica y legal de esta comunidad -constituida en municipio- para elaborar normas y ordenanzas del gobierno del agua. 
Tras la expulsión morisca de 1609, cada una de las nuevas familias cristianas que llegan a las poblaciones del Vinalopó recibe un lote de huerta. En Petrer las 100 familias reciben lotes iguales compuestos de casas, parcelas de regadío, olivar, viña y secano (Pérez Medina, 2011). Estos nuevos vecinos-regantes participan en los órganos de gobierno municipal estipulados en las nuevas cartas pueblas de 1611, que podían variar un tanto de un lugar a otro, pero que se atenían a las disposiciones y preceptos forales que tratan sobre los órganos municipales. Las Cortes valencianas aprobaron en 1283 la constitución de los municipios con sus cargos de libre elección anual entre el vecindario, por lo que las comunidades se convierten jurídica y legalmente en instancias de poder local (Guinot, 2007: 315). En las comunidades rurales de modelo municipal de gobierno del agua, la gestión y supervisión del sistema corresponde a la misma comunidad. El Consell General, máximo órgano de la administración local y asamblea decisoria de todos los vecinos, decide en asuntos importantes para la comunidad, entre los que se encuentran los riegos. Así, por ejemplo, el consejo general de Petrer se reunió el 25 de junio de 1651 para tratar sobre las nuevas excavaciones del los qanats de Puça y el 2 de septiembre de 1678 trató y debatió de fer un pantano en lo estret de Catí per que se està perdent la aygua de Catí des de la població. Es el Consell Particular, órgano colegiado constituido por los oficiales y magistrados comunitarios, el que más directamente interviene en la gestión del sistema hidráulico. Revisa y ordena las reparaciones y el mantenimiento del equipamiento básico en la red de riegos, gestiona las nuevas obras, elabora ordenanzas municipales...

Aquí tenemos, pues, una primera pauta de participación popular en los organismos colegiados de la comunidad, los consells, donde se reunían los vecinos-regantes en asamblea aldeana dotada con poder ejecutivo. En el estudio comparativo de Maass (2010: 38) un objetivo comunitario destacado es la participación popular en los órganos colectivos, en la elaboración de los procedimientos de gestión de sus sistemas de distribución y en la articulación de relaciones con otros sistemas y autoridades. Ostrom (2011), en su tercer principio de diseño de sistemas de recursos comunitarios, recoge la participación de los usuarios (vecinos-regantes) en los acuerdos de elección colectiva. Esta participación es universal en las villas postmoriscas donde todo el vecindario posee bienes similares -entre ellos huertas y agua-, pero el proceso de desposesión consiguiente, la segregación de tierra y agua y los cambios legales borbónicos aboliendo los concejos abiertos, hacen que la participación popular ejecutiva quede restringida a una minoría (Garrido, 2011: 22).

Pero hay otro tipo de participación popular: el vecino-regante colabora para hacer posible la práctica de la irrigación mediante la aceptación y aplicación de las reglas de juego elaboradas (Aguilera Klink, 2012). Los derechos al agua que reciben los vecinos se relacionan directamente con la pertenencia a la comunidad y con la participación en la actividad comunitaria. Para ello es preciso que las reglas indiquen a quien van a beneficiar o perjudicar, esto es, en palabras de Ostrom, establecer unos límites claros para el uso del agua, una supervisión de las condiciones del recurso y del comportamiento de los regantes, un sistema de sanciones iguales y mecanismos rápidos de regulación y/o resolución de conflictos. Todas estas normas, escritas o consuetudinarias, han de ser aceptadas por la comunidad participante. Han de aceptar las decisiones de los concejos y de los regidores locales relativas al buen estado y salubridad del agua, al mantenimiento de infraestructuras para la captación, circulación y regulación del agua y a los procedimientos operativos en la huerta. La manipulación directa del riego podía ser del campesino que regaba sus parcelas según las normas consuetudinarias o las ordenanzas municipales. Bases de la implicación popular en los procedimientos operativos son el autocontrol en el reparto del agua y la

\footnotetext{
${ }^{6}$ Arxiu Municipal de Petrer: Llibres de Consells (1648-1660), 49/2 y Caja 37, exp. 20.
} 
autovigilancia del sistema para el mantenimiento institucional -esto es, de las reglas de juego y de los hábitos de pensamiento y comportamiento (Aguilera Klink, 2012: 342). La organización comunitaria se basa en una firme autodisciplina y la pericia campesina (Maass, 1994).

En todas las comunidades hay un vecino-regante que es nombrado acequiero. Este oficial, al igual que otros, es miembro de la comunidad, no es un especialista ni forma parte de la burocracia local -que, por otro lado, es mínima en estos municipios. Las fórmulas de elección y nombramiento del acequiero varían en las diferentes poblaciones del Vinalopó. Observemos las cartas de población de 1611. El artículo 18 de la carta de Monòver indica que anualmente el vecindario nombrará, con la intermediación señorial, un justicia, un tinente, tres jurados, Almotacén, Sobrecequiero y Fiel de Aguas [...] que fueren nombrados para el gobierno y regimiento de dicha villa (Belando y Sánchez, 2011: 186). En todas las poblaciones aparece reglamentado el nombramiento de un sobresequier que, como en la trascripción anterior, también es calificado de repartidor de les aigües y fiel de las aguas. El nombramiento del acequiero estipulado en las cartas puebla varía en algunas poblaciones. Según las nuevas ordenanzas de aguas de 1726 de Villena, el alcalde o juez de aguas podría ser o no capitular del ayuntamiento; si no lo era asistiría a las sesiones capitulares con voz y voto siempre que se tratase de cuestiones relacionadas con los riegos ${ }^{7}$. En Bocairent los justicia $i$ jurats de dita vila de Bocayrent li donen tot lo poder que tenen com a senyors y administradors de dita aygua a lo qual sequier. Los jurados y justicia ordenaban al alguacil municipal que pregonase la subasta de la administració dels huyt dies del dret del aygua que dita vila té de la cèquia del Vinalopó. El vecino que, pujando a la baja, se quedaba con la administración era nombrado cequier de dita aygua de Vinalopó por un año, cuya función principal era la distribución del agua entre los vecinos de Bocairent y Banyeres de Mariola que tuviesen derecho a ella ${ }^{8}$.

Este cargo electo recibe diversos nombres en las comarcas del Vinalopó: sequier, acequiero, sobresequier, fiel de aguas, repartidor de aguas, juez. de aguas, alcalde de aguas. Glick (1988: 288-295) establece diferencias entre el abundante sobresequier, arabismo derivado de sabih al-saqiya, y el fiel de aguas, traducción literal del amin al-ma. Para las localidades del Vinalopó las diferencias se dan según el tamaño y la complejidad del espacio hidráulico. En las dos huertas de Elx coexisten el sobresequier con competencias jurídicas y el fiel de aguas que reparte los derechos de agua ${ }^{9}$. En la huerta de Petrer el almotacén asume durante muchos años las jurisdicción sobre les séquies, aigües $i$ pesos $i$ mesures, camins $i$ carrers $^{10}$. El sobresequier de Monforte regula y ordena el riego de la huerta; así, cuando el agua vaya en tanda lo brasal que comensara nol puxa dexar fins tant sia acabat. Para la conservación de las acequias posee poderes para ordenar la limpieza de sus cauces y cajeros y actúa sumariamente en casos de infracciones, aplicando sanciones: en la execusió de les penes sia beneplasi de dit sobresequier ${ }^{11}$. El concejo de Villena aprobó ordenanzas para el riego en 1530, 1583, 1704 y 1726 en las cuales se indica que cuando el agua vaya por tanda, son los acequieros los que deben dar el agua de los Cinco Hilos a los dichos días e a las horas que están ordenadas ${ }^{12}$ y tienen potestad para sancionar los agricultores que no atendiesen la reglamentación. En Elda se aprueban en 1615 los Capitols

\footnotetext{
${ }^{7}$ Archivo Municipal de Villena (AMV): Caja 9, exp. 43.

8 ARV: Procesos de Madrid: Letra B, no 164, fol. 76v. Pleito de 1609. El arrendamiento de las funciones de acequiero también aparece en la Séquia Major de Vila-Real en la baja edad media, Guinot y Selma, 2012: 125.

${ }^{9}$ Arxiu Històric Municipal d'Elx (AHME): Sección H, leg. H/173, exp. 12. Leg. H/23, exp. 30.

10 Arxiu Municipal de Petrer: Llibres de Consells (1611-1648), 49/1, 20 de noviembre de 1635. Llibres de Consells (1649-1660), 49/2, 30 de noviembre de 1658.

11 Archivo Municipal de Monforte: Llibres de Consells (1505-1553), Leg. 616, 31 de mayo de 1545.

12 AMV: Caja 725, exp. 23. Libros Capitulares, 15 de noviembre de 1583.
} 
del Sobresequier con la descripción de sus funciones ${ }^{13}$. En Monòver el acequiero tiene una caña de dotze pams para regular la limpieza de las acequias ${ }^{14}$. En Novelda el alamí tiene obligació de fer dos vęitas a la céquia entre semana y deba llevar un libro para asentar el agua repartida a los campesinos ${ }^{15}$. También en Aspe el fiel de aguas cuenta con un libro de aguas donde está anotada el agua que tienen los propietarios, el orden de riego, los días, las horas poseídas, las partidas a las que van dirigidas y si hay venta de la tanda ${ }^{16}$.

El funcionamiento del sistema hidráulico está garantizado por el control local ejercido desde la comunidad y sus órganos de gobierno, directamente con la emisión de ordenanzas y bandos, la ejecución de acuerdos de obras y reparaciones o a través de los acequieros y por la aceptación y participación de los vecinos-regantes. Estos oficiales del agua supervisan la distribución del agua y administran los derechos del agua según listados y calendarios rotativos de días y horas por turnos y tandas si están establecidos, ejercen la inspección con funciones ejecutivas del sistema hidráulico ordenando limpiezas y reparaciones, controlan los procedimientos operativos para que no hubiesen disrupciones e infracciones, actuando a la vez en la regulación de disputas y en la resolución de conflictos. Ostrom (2011: 92) considera que los costes de supervisión tenderán a ser más bajos si la vigilancia es realizada por los propios usuarios del sistema que si es realizada por una autoridad externa, a condición de que las reglas del juego también hayan sido diseñadas por los propios usuarios. Señala en su principio cuarto que puede existir un cuerpo de vigilantes (en nuestro caso los acequieros, pero puede ser también una vigilancia colectiva). La estructura física del sistema hidráulico y los procedimientos operativos aplicados (reducción de la ambigüedad en el reparto del agua, rotación, prioridad, participación de los usuarios...), permite la autovigilancia y la supervisión de los miembros de la comunidad (Glick, 2007: 112). La participación popular será efectiva y la aceptación de los órganos de gobierno y de los oficiales será mayor, cuando la actuación sea percibida por la comunidad como justa y equitativa (Maass, 2010: 421).

\section{Conclusiones}

Las villas del Vinalopó gestionan el uso comunitario del agua como si de un propio o común se tratara, por la cesión real o baronal. Glick (2007: 164) argumenta la dificultad para señorializar los sistemas de riego, ya que la interferencia baronal provoca una descomposición del sistema y una bajada de la renta extraída. En consecuencia, los señores mantienen la autonomía y el control local de los regantes para obtener los beneficios feudales. Cuando en 1611 se firman las nuevas cartas de población postmoriscas en el Vinalopó, la fórmula utilizada es la enfiteusis, con lo cual hay una división de dominios sobre la tierra y el agua que van unidas. La nobleza era consciente que para evitar la ruina económica y la quiebra de la renta feudal debía ceder el dominio útil al campesinado y junto a él la gestión del agua. La organización y la fuerza de las comunidades rurales, reconocidas legalmente en la legislación foral como municipios, respalda la gestión local del agua y de otros recursos comunales. Son poblaciones autónomas que controlan y gestionan el proceso de trabajo en torno a los recursos comunales de los cuales dependen (Rivera, 2009: 33). Los titulares feudales realizan un control indirecto con diferentes formas de dominación, explotación y producción en torno a la enfiteusis (Pérez Medina, e.p.).

\footnotetext{
13 Archivo Municipal de Elda: Manuals de Consells, 42/1.

14 ARV: Escibanías de Cámara: Año 1787, exp. 80.

${ }^{15}$ Arxiu Municipal de Novelda: exp. 3/04 (39).

16 AHME: leg. 53-A, no 6.
} 
El gobierno local del agua es más eficiente para ambas clases sociales, campesinado y nobleza feudal. El beneficio es alto para los vecinos-regantes locales por el cuidado cercano de sus recursos y por la previsión de flujos futuros, así como de la asignación del recurso y la participación popular para hacerla más eficiente y reducir los costes (Ostrom, 2011). Igualmente, en su principio octavo sobre estructuras anidadas, Ostrom señala que las decisiones operativas y ejecutivas diarias han sido tomadas por las comunidades, pero los órganos de gobierno superiores vigilan el desempeño local. Esto es, los delegados reales y señoriales supervisaban el funcionamiento del sistema hidráulico y las instancias gubernativas y judiciales regnícolas intervienen en coyunturas conflictivas y de envergadura. Las cartas puebla de 1611 establecen que todos los nuevos vecinos, mayormente campesinos, poseen tierras con agua de riego y participan en los órganos de gobierno local. Esta participación popular universal se fue reduciendo a lo largo de los siglos XVII y XVIII, tal como ocurrió en las villas que carecían de población musulmana desde la baja edad media (Bocairent, Villena o la vila de Elx). La desposesión de tierra y agua hace que una elite sea la que gestione el municipio y, por tanto, el agua. En el caso de Elx, los grandes propietarios exigieron el control de la administración del agua de la Séquia Major en 1785, asumiendo los gastos económicos de las reparaciones de las destrucciones sufridas por las estructuras hidráulicas tras una gran avenida del río Vinalopó. En 1789 se aprobaron las ordenanzas de la nueva Comunidad de Propietarios del Agua de la Acequia del Pantano de Elx. Por las mismas fechas, también la Acequia de Marxena ilicitana se constituyó como comunidad separada del municipio del Raval (Guinot y Selma, 2003: 7375). El control local queda en manos de la oligarquía propietaria y no del municipio. A finales del s. XVIII se instaura el modelo celular del gobierno del agua centrado en las comunidades de regantes de Elx. En Monòver, como ocurre en el resto de municipios del Vinalopó, continúa la gestión municipal del agua, pero a inicios del s. XIX es una minoría oligárquica la que dirige esta gestión.

\section{Referencias}

Aguilera Klink, F. (2012): "Elinor Ostrom, las instituciones y los recursos naturales de propiedad común: pensando con claridad más allá de las panaceas", Revista de Economía Crítica, 14, ps. 340-361.

Belando Carbonell, R. y Sánchez Recio, G. (2011): «Monnòver, una villa de señorío en el siglo XVII», Revista del Vinalopó, 14, ps. 167-189.

Blasco García, M.C. y Navarro i Belmonte, C. (2011): «El repoblament de la vila de Novelda després de 1609», Revista del Vinalopó, 14, ps.103-131.

Branchat, V. (1784-1786): Tratado de los derechos y regalias que corresponden al real patrimonio en el reyno de Valencia y de la jurisdicción del intendente, como subrogado en lugar del antiguo bayle general. València, 3 vols.

Brunhes, J. (1902): L'irrigation dans la péninsule Ibérique et dans l'A frique du Nord. París.

Cabanes Catalá, M. L. (1995): El còdex d’Elx. València, Generalitat Valenciana

Cariño, M. y otros (2013): Evocando el edén. Conocimiento, valoración y problemática del Oasis de los Comondú, Barcelona, Icaria Editorial.

Febrer Romaguera, M.V. (2000): Dominio y explotación territorial en la Valencia foral, València, PUV. 
García Sanz, A. (1986): Els furs. València, Generalitat Valenciana.

Garrido, S. (2011): "Las instituciones de riego en la España del este. Una reflexión a la luz de la obra de Elinor Ostrom", Historia Agraria. Revista de agricultura e historia rural, 53 ps. 1342 .

Giménez, M. y Palerm, J. (2007): “Organizaciones tradicionales de gestión del agua: importancia de su reconocimiento legal para su pervivencia. El caso de España", Región y Sociedad. Revista de El Colegio de Sonora, vol. XIX, nº 38, ps. 3-24.

Glick, T.F. (1988): Regadio y sociedad en la Valencia medieval. València, Del Cenia al Segura.

Glick, T.F. (1989): "Las técnicas agrícolas antes y después de la conquista", en En torno al 750 aniversaio. Antecedentes y consecuencias de la conquista de València, València, Generalitat Valenciana, ps. 53-71.

Glick, T.F. (1990): "El sentido arqueológico de las instituciones hidráulicas. Regadío bereber y regadío español", Aragón vive su historia. II Jonadas de Cultura Islámica, Madrid, Instituto Occidental de Cultura Islámica, ps. 165-171.

Glick, T.F. (1991a): Cristianos y musulmanes en la España medieval., Madrid, Alianza Editorial.

Glick, T.F. (1991b): "Sir Clements Markham i l'interés britànic en el regadiu hispànic a mitjan segle XIX", en Markham, C.R., Informe sobre el regadiu de l'Espanya de l'Est (1867), València, Alfons el Magnànim, ps. 7-44.

Glick, T.F. (1994): "Cap a una història institucional dels regs: un mètode d'estudi comparatiu”, Taller d'Història, 3, ps. 39-46.

Glick, T.F. (1995): “Arthur Maass y el análisis institucional del regadío en España”, Arbor, CLI, 593, ps. 13-34.

Glick, T.F. (2007): Paisajes de conquista. Cambio cultural y geográfico en la España medieval, València, PUV.

Gonzálvez Pérez, V. (1977): El Bajo Vinalopó. Geografía agraria. València, Departamento de Geografía de la Universitat de València.

Guinot, E (2007a): "El gobierno del agua en las huertas medievales mediterráneas: los casos de Valencia y Murcia" en Ser Quijano, G. del y Martín Viso, I (eds.), Espacios de poder y formas sociales en la Edad Media. Estudios dedicados a Ángel Barrios, Salamanca, Universidad de Salamanca, ps. 99-118.

Guinot, E. (2007b): "Comunidad rural, municipios y gestión del agua en las huertas medievales valencianas", en Rodríguez, A. (ed.), El lugar del campesino. En torno a la obra de Reyna Pastor, València, PUV-CSIC, ps. 309-330.

Guinot, E. y Selma, S. (2003): Acequias de Elche y Crevillente, València, Generalitat Valenciana.

Guinot, E. y S. Selma (2012): "La construcción del paisaje en una hueta feudal: la Séquia Major de Vila-Real (siglos XIII-XV)", en Torró, J. y Guinot, E., Hidráulica agraria y sociedad feudal. Prácticas, técnicas, espacios, València, PUV, ps. 103-145.

Holben, S.A. (2004): "La multifuncionalidad de asociaciones de regantes en el nivel local, Cochabamba, Bolivia", Boletín del Archivo Histórico del Agua, número especial "Organizaciones autogestivas para el riego", año 9, ps. 15-22.

Llauradó, A. (1878): Tratado de aguas y riegos, Madrid.

Maass, A. (1994): "Estructuras de poder y cohesión social en los sistemas de regadío de los EEUU y el levante español", en Romero, J. y Jiménez, C. (eds.), Regadíos y estructuras de poder, 
Alacant, IC Juan Gil-Albert, ps. 41-51.

Maass, A. y Anderson, R.L.: (2010): Los desiertos reverdecerán. Estudio comparativo de la gestión del riego en el Mediterráneo español y el Oeste norteamericano, València, Biblioteca Valenciana.

Martínez Español, G. (2011): «La carta puebla de Aspe. Características del régimen señorial tras la repoblación", Revista del Vinalopó, 14, ps. 133-163.

Monjo, M. (2012): “La pervivencia del regadío andalusí en la Aitana bajomedieval", en Torró, J. y Guinot, E., Hidráulica agraria y sociedad feudal. Prácticas, técnicas, espacios, València, PUV, ps. 207-224.

Ostrom, E. (2011): El gobierno de los bienes comunes. La evolución de las instituciones de acción colectiva, México, UNAM-FCE.

Palerm-Viqueira, J. (2005): "Gobierno y administración de sistemas de riego", Región y Sociedad. Revista de El Colegio de Sonora, vol. XVII, nº 34, ps. 3-33.

Pérez Medina, T. (1995): La tierra y la comunidad rural de Petrer en el siglo XVII. Petrer, Ayuntamiento de Petrer y Universidad de Alicante.

Pérez Medina, T. (1997): "Dinamismo y continuidad en los espacios hidráulicos de las comarcas del Vinalopó (1500-1836)", Agua y territorio. I Congreso de estudios del Vinalopó, Alacant, CEL Vinalopó, ps. 35-70.

Pérez Medina, T. (2011): "Senyoria i camperolat a la carta de poblament de Petrer (1611)", Revista del Vinalopó, 14, ps. 29-52.

Pérez Medina, T. (e.p.): "Relacions agràries de classe a les cartes de poblament de 1611 del migjorn valencià", Recerques.

Peris Albentosa, T. (2014): "El ejercicio de la autonomía local en las acequias de la huerta de Valencia: la olvidada imbricación municipal (siglos XIII-XIX)", DT-SEHA, 14-04.

Retamero, F. (2009): "La sombra alargada de Wittfogel. Irrigación y poder en al-Andalus", en Martín, M. (ed.), Al-Andalus/España. Historiografías en contraste. Siglos XVII-XXI, Madrid, Casa de Velásquez, ps. 263-293.

Rivera, J.A. (2009): La cultura de la acequia. Agua, tierra y comunidad en el Suroeste de los Estados Unidos de América, València, PUV.

Sánchez Recio, G. (2011): “Carta de población del señorío de Elda, 1611-1612”, Revista del Vinalopó, 14, ps. 191-211.

Wittfogel, K.A. (1966): Despotismo oriental. Estudio comparativo del poder totalitario. Madrid, Guadarrama. 